\title{
A Glimpse into the Virtual Community of Practice (CoP): Knowledge Sharing in the Wikipedia Community
}

\author{
Berto Usman* and Yennita
}

\begin{abstract}
Manuscript type: Research paper

Research aims: This paper aims to revisit the concept of the virtual community of practice among undergraduates in Italy and Indonesia. Design/Methodology/Approach: This study employs a quantitative approach to retrieve data from a questionnaire survey. Data are collected from undergraduate students of the business faculty from the University of Padua, Italy and the University of Bengkulu, Indonesia. Based on a systematic sampling method, the questionnaires are distributed through several social media platforms such as WhatsApp, e-mail, Messenger and Facebook. Analysis is conducted via Structural Equation Modeling (SEM).

Research findings: The findings highlight that Wikipedia characteristics and member promotion, community trust and community identification are found to be positively related to knowledge sharing intention. There is insubstantial evidence to demonstrate the significant effect of community participation on knowledge sharing intention.
\end{abstract}

\footnotetext{
* Corresponding author: Berto Usman is an Assistant Professor in Finance at the Department of Management, Faculty of Economics and Business, University of Bengkulu, Jln. WR Supratman, Kandang Limun 38121 Kota Bengkulu, Indonesia. Email: berto_usman@unib.ac.id Yennita is an Associate Professor at the Faculty of Teacher Training and Education, University of Bengkulu, Jln. WR Supratman, Kandang Limun 38121 Kota Bengkulu, Indonesia. Email: yennita@unib.ac.id

Acknowledgement: We are grateful to AJBA's editors, anonymous reviewers, Eleonora Di Maria, Matin Mohaghegh (University of Padua), Anggia Paramitha (University Riau), Anne Malau Rumondang (Universitas HKBP Nommensen), Mega Asri Zona (Universitas Negeri Padang), Rahman Febliansyah (Universitas Bengkulu) for their comments and extensive discussion given to the theoretical point of view and the statistical method used in this study.
}

https://doi.org/10.22452/ajba.vol11no2.8 
Theoretical contribution/Originality: This study expands on existing literature on virtual community of practice by offering a comparative analysis of two different samples from Italy and Indonesia.

Practitioner/Policy implications: The findings of this study suggest that virtual communities of practice are important vehicles of knowledge sharing in universities. However, many approaches need to be taken in order to ensure that the distribution and circulation of knowledge is properly conducted among members so as to sustain the dynamics of knowledge sharing in the community of practice.

Research limitation: Future research needs to emphasise on collecting data from diverse respondents in different geographical settings so as to increase the generalisability of the findings.

Keywords: Wikipedia, Community of Practice, Virtual Community Outcomes, Knowledge Sharing

JEL Classification: O30, O32, O35

\section{Introduction}

The amount of knowledge produced in today's academic environment is increasing profoundly. Such knowledge is significantly different from the information and knowledge that had been produced decades ago. As noted by Barker (2015), this phenomenon is triggered by the remarkable evolution and progress of Information Communication and Technology (ICT), where the Internet communication (Web 2.0) and technology (computer and gadgets) has given users a broad opportunity to acquire news and information easily. It also acts as support in terms of the simplification of process knowledge sharing. This phenomenon also reflects that the time, focus, scope and scale of academic knowledge production and sharing, have changed dramatically (Black, 2008). Academics, practitioners, and both public and private institutions working on the area of technological development, are beginning to connect collective resources and knowledge through the Internet platform and various other ICTs. The rapid development of the ICTs has been supporting the many interactions happening in cyberspace for community formation. This has led to the development of virtual communities which have helped to accelerate the growth of human beings, acting as bridges linking the digital gaps and addressing sustainable development goals.

In the community of practice, knowledge sharing is deemed to be one of the fundamental factors of the interaction. As long as the 
distribution and circulation of knowledge is properly conducted among members, the dynamics of knowledge sharing in the community of practice will be sustained (Jensen, Johnson, Lorenz, \& Lundvall, 2007). Currently, the community of practice is not only manifested in the physical form and the routine meetings of members (Schwen \& Hara, 2003; Md. Rasli \& Wan Mohd, 2007; Wenger \& Trayner-Wenger, 2015) but also through many other virtual community of practices (CoP) that allow members to interact in cyberspace media. Wikipedia, STATALIST (the Stata forum), Linux programmer platform, online distance learning, chat rooms, the virtual world and so forth are new modes for knowledge sharing activities; they are unrestrained by time and space, and they focus on immediate responses and interactions (Gray, 2004; Jansen, Sobel, \& Cook, 2011; Kim, Sohn, \& Choi, 2011).

The significant increase noted in the number of users and contributors of Wikipedia illustrates that this platform is taking on the role as an intelligent entity in the virtual community setting (Trkman \& Trkman, 2009). In this regard, people are inclined towards producing and consuming information that is preserved in and accessed from various sources (Black, 2008; Johnson, 2001). It was also observed that the existence of the same joint enterprises, mutual engagement and shared repertoire among users and contributors enabled them to enjoy the same interest through different platforms of knowledge sharing activities (online and non-online) (Wenger, 2003). Given the important role played by the virtual community in today's knowledge sharing practices, many studies have thus been conducted to examine this phenomenon. Among them, Wang and Wei (2011) reported that the Wiki application has a direct and positive effect on the virtual community's outcomes (community participation, promotion, trust and identification). The Wiki application is related to the Wiki members' willingness to share knowledge and how they behave. In an earlier study, Korfiatis, Poulos and Bokos (2006) evaluated the authoritative source of the social network by focusing on Wikipedia as the knowledge circulation platform. They noted that as Wikipedia advances to become a virtual community of practice, it was also barraged by the critical issue of credibility as an authoritative reference source. This issue challenged the contributors as members to keep maintaining and sustaining the reliability of the contents in knowledge value creation and circulation.

In another study, Chiu, Wang, Shih and Fan (2011) examined how individuals could be encouraged to participate and share knowledge in a virtual community of practice. They suggested that playfulness 
can be a critical factor in encouraging the continuance intention of virtual community knowledge sharing. Recently, there have been exploratory studies which surveyed how individuals used the virtual community of practice. Hafeez, Alghatas, Foroudi, Nguyen and Gupta (2018), for example, examined how entrepreneurs engaged in a virtual community of practice to share their knowledge. They observed that entrepreneurs used short and medium messages to contribute to the discussions in the virtual community of practice. They also noted that the engaged topics usually enhance the discussions, thereby promoting the discussion threads. In one longitudinal study, Gray and Gabriel (2018) noticed that self-employed and unemployed managers used the virtual community of practice to share their knowledge and experiences in start-up businesses. They noted that the presence of diversity within the community provided rich professional insights as well as tensions for the members. Hence, it was proposed that such a virtual community of practice would require a moderator who is able to coordinate contributions and to respect cultural differences, simultaneously. Current literature indicates that very few studies are able to explain the use of Wikipedia as a virtual community. Of those that do, they seemed to rely entirely on exploratory data coupled by limited examples drawn from developing country settings.

Motivated by the limitation of existing literature, this study hence aims to address several key areas in terms of knowledge sharing in the virtual community of practice. First, it strives to look at the Wikipedia as a community of practice platform by showing members' involvement in using the virtual community of practice and their outcomes. Second, this study attempts to compare how two different groups of Wikipedia users from Italy and Indonesia, engage in the Wikipedia as a virtual platform. In that regard, the outcome offers empirical evidence to support the findings hence contributing to literature. Following the steps of Wang and Wei's (2011) focus of investigation, this study thus comprehensively investigates the current phenomenon of the Wikipedia as a virtual community of practice by addressing the following research questions: 1) what is the current condition of the virtual community of practice among the Wikipedia members and users in the context of Italy and Indonesia? 2) What is the common demographical profile of the Wikipedia members and users in the context of Italy and Indonesia? 3) Are there any differences in the users' perception with regards to their knowledge intention while using the Wikipedia platform? 4) What is the relationship between the Wikipedia characteristics, the 
virtual community outcomes and the knowledge sharing intention among the users?

In this study, Italy and Indonesia were determined as the targeted context due to their high involvement as the TOP 20 Internet countries with the highest number of Internet users within Europe and Asia (Stats, 2018). As of September 2018, the number of Wikipedia contributors in Italy has grown to 58,636 contributors while the number from Indonesia was reported to be 12,636 . Both countries are listed among the higher contributors to Wikipedia, according to the Wikipedia statistics database (WMF Analytics, 2018). In this context, we conjecture that the high number of Internet users may be integrated with the Internet usage. Thus, we focus on Wikipedia as a virtual-based community of practice for one developed country (European Union) and one developing country (ASEAN). We also speculate some possible and significant differences in the practice and routines of using the Wikipedia as a sharing platform in the virtual community outcome, as a result of differences in cultural values and behaviour.

The remainder of this paper is structured as follows: Section 2 highlights the literature review by explaining the major theoretical foundations of the current trend of community of practices. Section 3 presents the method of data collection. Section 4 reports and discusses the findings, and Section 5 concludes with the implications of this study.

\section{Literature Review}

\subsection{Wikipedia Characteristics}

The online Wikipedia was launched in 2001. Its aim was to serve as a free encyclopedia in multiple languages (Black, 2008). The Wikipedia allows users to contribute to the subject matter with resources enabling them to edit, add and remove the contents freely. Different from other virtual CoP platforms, there is no specific information about the entries' contributors although in some cases member registration is needed before they could proceed to the content contribution (Rector, 2008). Given these characteristics, the Wikipedia appears to be a medium that stimulates quick discovery; it is also a useful learning tool that fosters knowledge sharing activities among the online community members (Ebner, Kickmeier-Rust, \& Holzinger, 2008). Common knowledge among members is characterised as the fundamental capability for members to interactively and collaboratively engage with the computer- 
mediated communication such as the Wikipedia (Parker \& Chao, 2007). The characteristics of such a relationship were eventually considered as the triggering factor, particularly in boosting opportunities which create plausible interactions among users and members (Bruns \& Humphreys, 2005; Ebner et al., 2008).

Due to the huge amount of data and notes contributed and shared by users, the Wikipedia has finally enlarged its coverage to turn into a webpage that corresponds to the storing and modifying of information activities. More specifically, the Wikipedia has continued to grow in terms of the number of articles being published on the Wiki ${ }^{1}$ pages. The number of scripts and articles added to the Wikipedia through the Wiki pages mode, has grown significantly since the past subsequent years (Trkman \& Trkman, 2009). Currently, the number of articles written in English in the first quarter of 2017 was noted to be 5,416,803 articles with the total Wiki pages noted to be $42,234,457$ pages. As of the first quarter of 2017, the number of contributors and users had reached 1,259 and 31,072,435, respectively (Wikipedia, 2017).

\subsection{Virtual Community Outcomes}

The concept of a virtual community is defined by Balasubramanian and Mahajan (2001) as an entity that displays several major characteristics comprising: (i) the aggregation of people within the group, (ii) rational utility-maximiser among members, (iii) interpersonal interactions in terms of cyberspace that is not followed by the physical co-location, (iv) the social-exchange process found in the interaction and $(\mathrm{v})$ the presence of a shared property or identity, objective and or interest among members. With regards to the virtual community and its relation to knowledge sharing, it is believed that the degree of knowledge sharing takes an important role in expanding the use of the virtual community

\footnotetext{
${ }^{1}$ As noted in the paper by Ebner et al. (2008), the first pilot project of wikis was introduced by Bo Leuf and Ward Cunningham in 1995 (Leuf \& Cunningham, 2001). The term wiki itself was derived from "wikiwiki", which in Hawaiian, denotes as "quick" (basic word of fast). In the wiki system, every user and member is not only able to create his/her own articles but also to remove, edit, revise, extend, or link the existing article with other existing and relevant links in the same tag category. Also, the original aim of the wiki establishment was to develop an easy-to-use knowledge management system which enables effective and efficient online collaboration among members in the online-based virtual community of network. Therefore, the wiki system provides a mark-up language feature. This system is based on the simplification of the HTML element which reduces the very basic tags in the online content (Elrufaie \& Turner, 2005; Wang \& Turner, 2004).
} 
(Zhang, Fang, Wei, \& Chen, 2010). It was highlighted by Wasko and Faraj (2000) that productive knowledge sharing is more likely to be the determining factor of an effective virtual community. This is important since the satisfaction of members is influenced by the level of knowledge sharing among members within the group.

Due to the remarkable progress of technology which has shifted the manual community of practice to one that is digital, many researchers (Ardichvili, Page, \& Wentling, 2003; Johnson, 2001; Koh \& Kim, 2004; Liao, To, \& Hsu, 2013) have been striving to understand how the latter works as a valuable and effective system in facilitating the process and activity of knowledge sharing. Due to this transformation, the virtual community has been regarded as resembling the real-life community where the virtual or online-based community, has to also support and provide information among members, thereby allowing the members or participants to increase their involvement and interaction. In this regard, the usage of the virtual community of practice can be perceived as containing a variety of professional and non-professional purposes. Di Maria and Finotto (2008) noted that the online entity somehow relied on user communities; it requires structured and focused marketing strategies which is in line with the characteristics of the virtual community. They act as key elements to maintaining the sustainability of the entity depending on brands, communication and interactions.

Several studies (e.g. Romm, Pliskin, \& Clarke, 1997; Wang \& Wei, 2011; Liao et al., 2013) have shed light on the online-based community of practice by looking at virtual community outcome factors. The importance of the virtual community outcomes correspond to the success of the knowledge sharing activity. The characteristics and member interaction are themselves not enough if these factors are not followed by the active participation, promotion, interpersonal trust and identification within groups. Many researchers have pointed out the essence of the virtual community in fostering the process of knowledge sharing intention in online-based community of practice. Table 1 illustrates.

\subsection{Knowledge Sharing}

The process of knowledge sharing can only be fulfilled by at least two parties (knowledge owners and knowledge receivers) who are involved in the sharing activities. According to Hendriks (1999), knowledge sharing carries four primary perspectives. First, there is communication between at least two parties. Second, there is a procedure and a 
Table 1: Prior Studies on the Online-Based Community of Practice

\begin{tabular}{|c|c|c|}
\hline $\begin{array}{l}\text { Virtual Community } \\
\text { Outcomes }\end{array}$ & Author(s) & Findings \\
\hline $\begin{array}{l}\text { Community } \\
\text { Participation (CPA) }\end{array}$ & $\begin{array}{l}\text { Romm et al. (1997), } \\
\text { Wang and Wei (2011), } \\
\text { Shaw and Hargittai (2018) }\end{array}$ & $\begin{array}{l}\text { Due to the existence of the same } \\
\text { interest and needs among the } \\
\text { members, voluntary activities are } \\
\text { found to be strong among virtual } \\
\text { community members. }\end{array}$ \\
\hline $\begin{array}{l}\text { Community } \\
\text { Promotion (CPR) }\end{array}$ & $\begin{array}{l}\text { Koh and Kim (2004), } \\
\text { Liao et al. (2013), } \\
\text { Pee (2018) }\end{array}$ & $\begin{array}{l}\text { The success of the virtual com- } \\
\text { munity depends on the users' } \\
\text { interest, willingness to promote } \\
\text { and provide the knowledge in } \\
\text { their community. }\end{array}$ \\
\hline $\begin{array}{l}\text { Community Trust } \\
\text { (CT) }\end{array}$ & $\begin{array}{l}\text { Casimir, Lee and Loon } \\
\text { (2012), Ebner et al. (2008), } \\
\text { Wang and Wei (2011) }\end{array}$ & $\begin{array}{l}\text { It is sometimes difficult to define } \\
\text { the trust among the contents of } \\
\text { knowledge provided by online- } \\
\text { based platform systems. How- } \\
\text { ever, the willingness of a com- } \\
\text { munity to act based on a set of } \\
\text { beliefs and norms can increase } \\
\text { the trust of members in the } \\
\text { knowledge sharing activities. }\end{array}$ \\
\hline $\begin{array}{l}\text { Community } \\
\text { Identification (CI) }\end{array}$ & $\begin{array}{l}\text { Chiu, Hsu and Wang } \\
\text { (2006), Wang and Wei } \\
\text { (2011) }\end{array}$ & $\begin{array}{l}\text { The sense of belonging among } \\
\text { users and members can only be } \\
\text { built if they perceive the same set } \\
\text { of beliefs, norms and also similar } \\
\text { long-term interests in online- } \\
\text { based community of practice. }\end{array}$ \\
\hline
\end{tabular}

perceived learning activity. Third, the availability of the market is clear and fourth, there is interaction among the members.

Referring to the modes of knowledge sharing as proposed by Nonaka, (1994) (Figure 1), it can be seen that the third mode of the SECI (socialisation, externalisation, combination and internalisation) model is a "combination" involving the use of the social process to combine different bodies of explicit knowledge held by individuals. On a similar note, some scholars believe that the act of knowledge sharing is based on the social exchange theory since the outcome of the exchange process leads to a behaviour change. According to the social exchange theory, an individual would commonly weigh the potential benefits and risks 


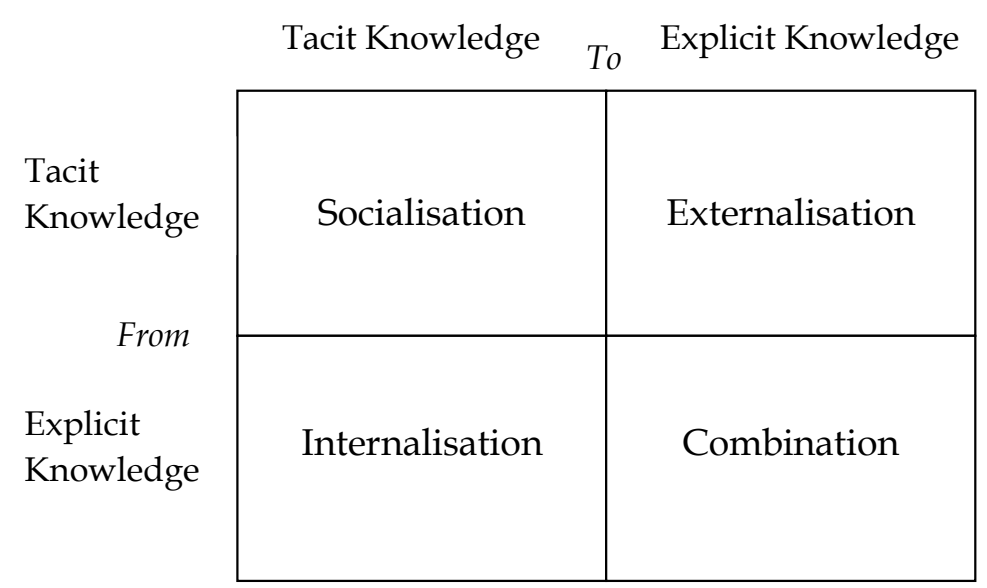

Figure 1: Modes of Knowledge Creation

Source: Nonaka, 1994.

of the social relationship prior to interaction. In the context of the virtual $\mathrm{CoP}$, the likelihood of individuals sharing the information is higher when they are able to maximise the benefits obtained from sharing the knowledge (Bettiol, Di Maria, \& Grandinetti, 2012; Molm, 1997). According to Nonaka (1994), the individual exchange and the combined knowledge can be done through exchange mechanisms such as meetings or telephone conversations. Presently, the model of communication has been progressively upgraded by more sophisticated technologies and knowledge management repository approaches (Massingham, 2014). The explosive Internet diffusion, for instance, has boosted the proliferation of virtual communities (Liao et al., 2013). The combination of people and technology platforms is today prolific, in the form of online-based platform communities such as the Wikipedia (Shaw \& Hargittai, 2018). The reconfiguration of existing information as seen in current technological platforms, enable the members to maintain the virtual community either by adding, re-categorising or re-contextualising the data and information more easily. Figure 1 demonstrates.

\subsection{Research Model and Hypothesis Development}

The model used to illustrate the relationship between Wikipedia appli-cation, the virtual community outcomes and the behaviour in knowledge sharing is displayed in Figure 2. It is adopted from Wang and Wei (2011). This model is composed of seven factors which are 


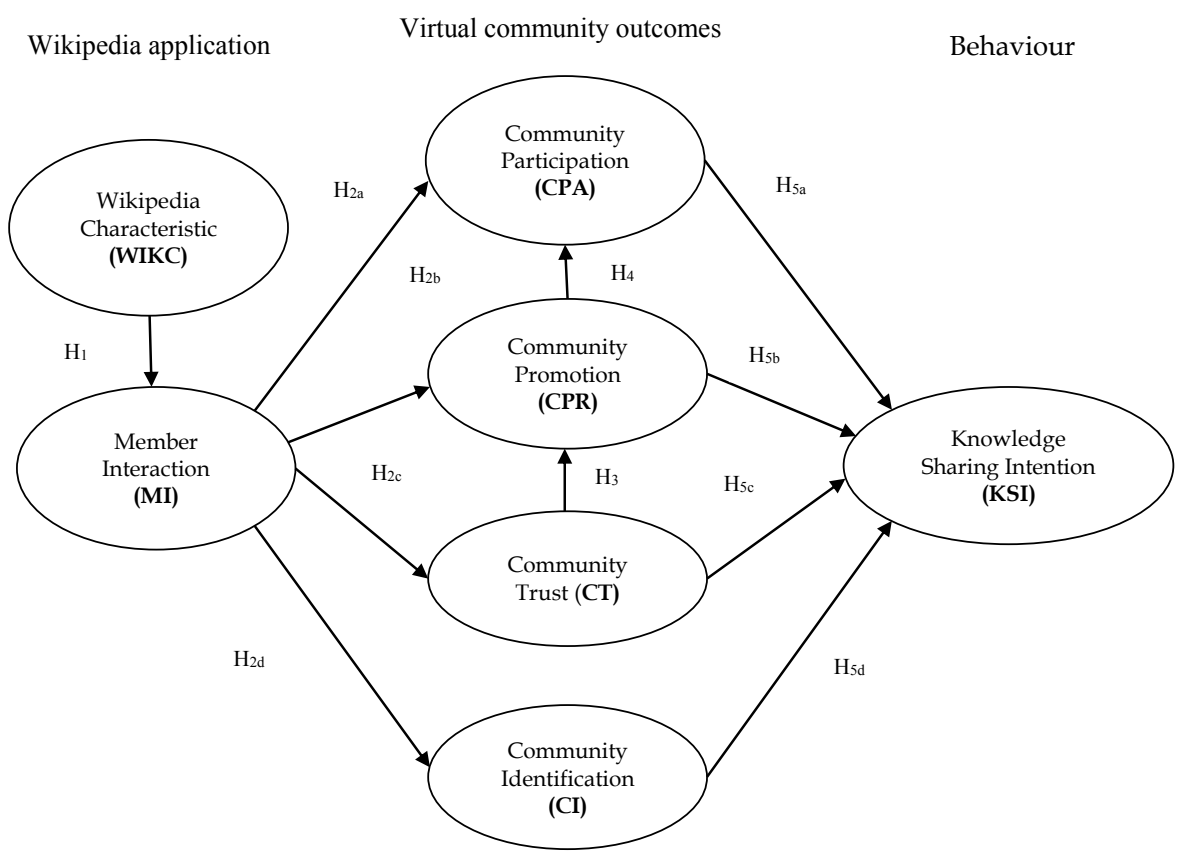

Figure 2: The Proposed Model of Virtual Community Outcomes Source: Wang \& Wei, 2011.

expected to show the relationship between the dimensions of the Wikipedia application, the virtual community outcomes and the behaviour in knowledge sharing. It can be seen that the Wikipedia application has two factors: Wiki characteristics (WIKC) and member interaction (MI). The virtual community outcomes at the manifestation of the community of practice in the online-based community have four factors: community participation (CPA), community promotion (CPR), community trust (CT) and community identification (CI). The last of this, the behaviour is depicted by the usage of knowledge sharing intention (KSI) among the members.

\subsubsection{The Association between Wikipedia Characteristic, Member Interaction, and Community of Outcomes}

Hansen, Berente and Lyytinen (2009) had explored the Wikipedia as a platform for rational discourse and as a manifestation of communicative actions. It was noted that in more developed discussions, interactions 
among users and members in the virtual community of practice such as the Wikipedia can be classified as a combination of between peopleto-people interaction and as a codification of from people-to-document (see Nonaka's (1994) modes of knowledge creation). Moreover, the procedure of knowledge circulation among members is conducted through the mechanism of many-to-many people. The related information is easily and timely distributed among members. Therefore, the characteristic of the virtual CoP such as Wikipedia creates a huge impact in stimulating high level participation and interaction among members. Besides the interaction itself, interpersonal connection in terms of manyto-many relationship, is conjectured to be positive if members carefully recognise the importance and legitimacy of online-based community practices (Wasko \& Faraj, 2000). This will eventually lead to virtual community outcomes that drive the variation in the behaviour of the members. Also, the perceived ease of use of the application is considered as the determinant factor of member interaction (Romm et al., 1997). The interpersonal relationship among members is expected to increase community participation, community promotion, community trust and community identification among the members. Based on the a priori explanation of the relationship between the Wikipedia characteristics and member interaction and virtual community outcomes, this study thus postulates that:

$\mathrm{H}_{1}$ : Wikipedia characteristics (WIKC) among the members are positively related to member interaction (MI).

$\mathrm{H}_{2 \mathrm{a}}$ : Member interaction (MI) in the Wikipedia community is positively related to community participation (CPA).

$\mathrm{H}_{2 \mathrm{~b}}$ : Member interaction (MI) in the Wikipedia community is positively related to community promotion (CPR).

$\mathrm{H}_{2 \mathrm{c}}$ : Member interaction (MI) in the Wikipedia community is positively related to community trust (CT).

$\mathrm{H}_{2 \mathrm{~d}}$ : Member interaction (MI) in the Wikipedia community is positively related to community identification (CI).

\subsubsection{The Association between Virtual Community Outcomes and Knowledge Sharing Intention}

The interaction among members and users can increase due to the presence of trust among members of the virtual community (Massingham, 2014). In the absence of the teacher-student role that commonly 
takes place in physical learning and knowledge sharing environments, trust is important for maintaining and sustaining the virtual CoP. In the virtual environment, there is no guarantee that the information or knowledge shared is valid and genuine. Therefore, trust is necessarily important for the group where the existence of trust will eventually increase member promotion. When there is a strong level of trust, members are more likely to promote the virtual community or to invite new potential knowledge contributors (Kim et al., 2011). With more proactive and aggressive members promoting the virtual community to new knowledge contributors, an increase in community participation is likely to happen. Intensive postings, for example, would help in promoting the virtual community. With more members and new contributors viewing the postings, ideas and knowledge are disseminated quickly. This too increases community participation. The more people participate as contributors, the more the knowledge is shared among the community. Based on the above arguments, this study postulates that:

$\mathrm{H}_{3}$ : Community trust $(\mathrm{CT})$ in the Wikipedia community is positively related to community promotion $(\mathrm{CPR})$ of the virtual community.

$\mathrm{H}_{4}$ : Community promotion (CPR) in the Wikipedia community is positively related to community participation (CPA) of the virtual community.

$\mathrm{H}_{5 \mathrm{a}}$ : Community participation (CPA) in the Wikipedia community is positively related to the knowledge sharing intention (KSI) of the virtual community.

$\mathrm{H}_{5 \mathrm{~b}}$ : Community promotion (CPR) in the Wikipedia community is positively related to the knowledge sharing intention of the virtual community.

$\mathrm{H}_{5 \mathrm{c}}$ : Community trust $(\mathrm{CT})$ in the Wikipedia community is positively related to the knowledge sharing intention (KSI) of the virtual community.

Community identification is a form of social attachment observed in virtual community groups (Lee, Ahn, \& Han, 2007). The members of the virtual community develop a sense of identification to the extent that the virtual community can meet their needs and desires (Qu \& Lee, 2011). Highly attached members tend to be more interested in the shared topics of conversation and this leads to the development of relationships with other members. They are more willing to contribute to the virtual community by giving more frequent information, opinions and sharing 
experiences with other members (Arnett, German, \& Hunt, 2003). Based on these arguments, this study postulates that:

$\mathrm{H}_{5 \mathrm{~d}}$ : Community identification (CI) in the Wikipedia community is positively related to the knowledge sharing intention (KSI).

\section{Research Methodology}

This study employs a quantitative technique using the questionnaire survey as a data collection approach. To test the research framework of the questionnaire, items were adopted from previous literature (Koh \& Kim, 2004; Wang \& Wei, 2011). The five-point Likert scale is used to measure the variables. The operationalisation of these variables is depicted in Table 2.

Table 2: Variable Measurements

\begin{tabular}{|c|c|c|c|}
\hline Variables & & Items & Source \\
\hline \multirow[t]{6}{*}{$\begin{array}{l}\text { Wikipedia } \\
\text { Characteristic }\end{array}$} & WIKC1 & $\begin{array}{l}\text { The Wikipedia applications of my virtual } \\
\text { community allow me to collaborate with } \\
\text { other community members to develop or } \\
\text { edit the content published in my virtual } \\
\text { community. }\end{array}$ & \multirow[t]{6}{*}{$\begin{array}{l}\text { Wang and } \\
\text { Wei (2011) }\end{array}$} \\
\hline & WIKC2 & $\begin{array}{l}\text { The content published in the pages of my } \\
\text { virtual community is generated through } \\
\text { group interactions of our members. }\end{array}$ & \\
\hline & WIKC3 & $\begin{array}{l}\text { The Wikipedia versioning capability of my } \\
\text { virtual community permits rollbacks in the } \\
\text { event that document modifications need to } \\
\text { be undone. }\end{array}$ & \\
\hline & WIKC4 & $\begin{array}{l}\text { The pages in my virtual community are } \\
\text { well-organized based on the topics and } \\
\text { versions of the content presented, which } \\
\text { allows me to read or edit the content easily. }\end{array}$ & \\
\hline & WIKC5 & $\begin{array}{l}\text { The Wikipedia applications used in my } \\
\text { virtual community can organize the } \\
\text { content published based on a logical flow } \\
\text { of ideas, which allows me to easily acquire } \\
\text { knowledge related to a specific area. }\end{array}$ & \\
\hline & WIKC6 & $\begin{array}{l}\text { I can easily access and use the Wikipedia } \\
\text { applications of my virtual community } \\
\text { anytime I want. }\end{array}$ & \\
\hline
\end{tabular}


Table 2: (continued)

\begin{tabular}{|c|c|c|c|}
\hline Variables & & Items & Source \\
\hline \multirow[t]{4}{*}{$\begin{array}{l}\text { Member } \\
\text { Interaction }\end{array}$} & MI1 & $\begin{array}{l}\text { The design of the collaborative tools of } \\
\text { our virtual community enables me to } \\
\text { make a more realistic judgment of the } \\
\text { information acquired. }\end{array}$ & \multirow[t]{4}{*}{$\begin{array}{l}\text { Wang and } \\
\text { Wei (2011) }\end{array}$} \\
\hline & MI2 & $\begin{array}{l}\text { The virtual interaction enabled by our } \\
\text { community can promote superior } \\
\text { relationships among community members. }\end{array}$ & \\
\hline & MI3 & $\begin{array}{l}\text { The design of the collaborative tools of our } \\
\text { virtual community enables me to get an } \\
\text { understanding of the topics of interest. }\end{array}$ & \\
\hline & MI4 & $\begin{array}{l}\text { The functions of our virtual community } \\
\text { can provide me with more freedom for } \\
\text { interactions. }\end{array}$ & \\
\hline \multirow[t]{4}{*}{$\begin{array}{l}\text { Community } \\
\text { Participation }\end{array}$} & CPA1 & $\begin{array}{l}\text { I often provide useful information/content } \\
\text { for our virtual community members. }\end{array}$ & \multirow[t]{4}{*}{$\begin{array}{l}\text { Wang and } \\
\text { Wei (2011) }\end{array}$} \\
\hline & CPA2 & $\begin{array}{l}\text { I eagerly reply to postings by the help- } \\
\text { seeker of our virtual community. }\end{array}$ & \\
\hline & CPA3 & $\begin{array}{l}\text { I take care of our virtual community } \\
\text { members. }\end{array}$ & \\
\hline & CPA4 & $\begin{array}{l}\text { I often help our virtual community } \\
\text { members who seek support from other } \\
\text { members. }\end{array}$ & \\
\hline \multirow[t]{5}{*}{$\begin{array}{l}\text { Community } \\
\text { Promotion }\end{array}$} & CPR1 & $\begin{array}{l}\text { I invite my close acquaintances to join our } \\
\text { virtual community. }\end{array}$ & \multirow[t]{5}{*}{$\begin{array}{l}\text { Koh and } \\
\text { Kim }(2004\end{array}$} \\
\hline & CPR2 & $\begin{array}{l}\text { I often talk to people about the benefits of } \\
\text { our virtual community. }\end{array}$ & \\
\hline & CPR3 & $\begin{array}{l}\text { I often introduce my peers or friends to } \\
\text { our virtual community. }\end{array}$ & \\
\hline & CPR4 & $\begin{array}{l}\text { I say positive things about this community } \\
\text { to others. }\end{array}$ & \\
\hline & CPR5 & $\begin{array}{l}\text { I recommend this community to anyone } \\
\text { who seeks my advice. }\end{array}$ & \\
\hline \multirow[t]{3}{*}{$\begin{array}{l}\text { Community } \\
\text { Trust }\end{array}$} & CT1 & $\begin{array}{l}\text { By joining this online community, I will } \\
\text { save time in getting information }\end{array}$ & \multirow[t]{3}{*}{$\begin{array}{l}\text { Wang and } \\
\text { Wei (2011) }\end{array}$} \\
\hline & $\mathrm{CT} 2$ & $\begin{array}{l}\text { By joining this online community, I will } \\
\text { save money in getting information }\end{array}$ & \\
\hline & CT3 & $\begin{array}{l}\text { I can get specific information from this } \\
\text { online community }\end{array}$ & \\
\hline
\end{tabular}


Table 2: (continued)

\begin{tabular}{|c|c|c|c|}
\hline Variables & & Items & Source \\
\hline & CT4 & $\begin{array}{l}\text { The information I get from this online } \\
\text { community will help me improve my } \\
\text { abilities. }\end{array}$ & \\
\hline \multirow[t]{5}{*}{$\begin{array}{l}\text { Community } \\
\text { Identification }\end{array}$} & CI1 & $\begin{array}{l}\text { I feel a sense of belonging to my virtual } \\
\text { community. }\end{array}$ & $\begin{array}{l}\text { Wang and } \\
\text { Wei (2011) }\end{array}$ \\
\hline & $\mathrm{CI} 2$ & $\begin{array}{l}\text { I am glad that I joined my virtual } \\
\text { community for knowledge sharing } \\
\text { purposes. }\end{array}$ & \\
\hline & $\mathrm{CI} 3$ & $\begin{array}{l}\text { I have a strong positive feeling toward my } \\
\text { virtual community. }\end{array}$ & \\
\hline & CI4 & $\begin{array}{l}\text { I believe that this is my favourite virtual } \\
\text { community. }\end{array}$ & \\
\hline & CI5 & $\begin{array}{l}\text { I am proud to be a member of my virtual } \\
\text { community. }\end{array}$ & \\
\hline \multirow[t]{4}{*}{$\begin{array}{l}\text { Knowledge } \\
\text { Sharing } \\
\text { Intention }\end{array}$} & KSI1 & $\begin{array}{l}\text { I frequently participate in knowledge } \\
\text { sharing activities in this online } \\
\text { community. }\end{array}$ & $\begin{array}{l}\text { Wang and } \\
\text { Wei (2011) }\end{array}$ \\
\hline & KSI2 & $\begin{array}{l}\text { I usually spend a lot of time conducting } \\
\text { knowledge sharing activities in this online } \\
\text { community. }\end{array}$ & \\
\hline & KSI3 & $\begin{array}{l}\text { When participating in this online } \\
\text { community, I usually actively share my } \\
\text { knowledge with others. }\end{array}$ & \\
\hline & KSI4 & $\begin{array}{l}\text { I usually involve myself in discussions of } \\
\text { various topics rather than specific topics. }\end{array}$ & \\
\hline
\end{tabular}

The target population of this study were students who use the Wikipedia. Our sampling frame comprises undergraduate management students attached to the Dipartimento di Scienze Economiche e Aziendali (DSEA), "Marco Fanno", the University of Padua - (UNIPD, Italy), and the Departemen Manajemen, Fakultas Ekonomi dan Bisnis (FEB), the University of Bengkulu (UNIB, Indonesia). Currently, the University of Padua in Italy has 38,495 undergraduate students while the University of Bengkulu has around 7,927 undergraduate students. More precisely, we report the total number of students that is 600 active undergraduate students in the management studies at the University of Padua and 400 active undergraduate students at the University of 
Bengkulu. To systematically collect the samples, we pick every third student who was registered in the faculty's student database. The reason for using the students as the targeted respondents are as follows: First, university students are more easily available and accessible. Second, it is less expensive when engaging university students whilst seeking research respondents from outside the university will be more difficult in terms of time and finances. Third, the undergraduate students are predominantly familiar with using the Internet and one of the most accessed web pages they use to collect information is the Wikipedia page.

A total of 333 students were then approached through the email. Upon obtaining their consent for participation, 220 questionnaires were distributed through several social media such as WhatsApp's, email, Messenger and Facebook, depending on the preference of the respondents. The respondents were then equally distributed into two groups - Italians and Indonesians. Table 3 depicts the demographic profiles of the respondents.

Table 3: Demographic Profiles of Respondents in Two Countries

\begin{tabular}{|c|c|c|c|c|c|}
\hline \multirow{2}{*}{\multicolumn{2}{|c|}{$\begin{array}{l}\text { Demographic } \\
\text { Characteristics }\end{array}$}} & \multicolumn{2}{|c|}{ Italy } & \multicolumn{2}{|c|}{ Indonesia } \\
\hline & & \multirow{2}{*}{$\frac{\text { Frequency }}{64}$} & \multirow{2}{*}{$\begin{array}{c}\text { Percentage } \\
58.18\end{array}$} & \multirow{2}{*}{$\begin{array}{c}\text { Frequency } \\
76\end{array}$} & \multirow{2}{*}{$\begin{array}{c}\text { Percentage } \\
69.09\end{array}$} \\
\hline Gender & Male & & & & \\
\hline & Female & 46 & 41.82 & 34 & 30.91 \\
\hline \multirow[t]{4}{*}{ Age } & $<18$ years old & 18 & 16.36 & 8 & 7.27 \\
\hline & $19-21$ & 42 & 38.18 & 30 & 27.27 \\
\hline & $22-25$ & 35 & 31.82 & 48 & 43.64 \\
\hline & $26-29$ & 15 & 13.64 & 24 & 21.82 \\
\hline Internet & $<1$ year & - & - & - & - \\
\hline \multirow[t]{3}{*}{ Experience } & $1-3$ & 20 & 18.18 & 24 & 21.82 \\
\hline & $4-6$ & 36 & 32.73 & 28 & 25.45 \\
\hline & $>6$ years & 54 & 49.09 & 58 & 52.73 \\
\hline
\end{tabular}

As can be noticed, a majority of the respondents were males for both groups. In terms of age, most of the respondents from Italy were between 19 to 21 years old while most of the respondents from Indonesia were in the range of 22 to 25 years old. For both samples, a majority of the respondents appear to have more than six years of Internet experience. 


\section{Results and Discussion}

The structural equation modelling (SEM), using AMOS and a twostage model estimation was applied, in line with Anderson \& Gerbing (1988). The confirmatory factor analysis was conducted, followed by the structural model analysis.

\subsection{Measurement Model Analysis}

A measurement model encompassing all the variables of interest was evaluated. Two psychometric tests, the convergent validity and discriminant validity, were performed. The convergent validity was conducted to ensure that multiple items used to measure the variables are in agreement. In line with Hair, Hult, Ringle and Sarstedt (2016), the convergent validity was assessed based on factor loadings, composite reliability and average variance extracted (AVE). As indicated in Table 4, all the items' loading have significant values and are between the range of 0.513 and 0.838. This fulfils the requirement of this study (Bagozzi, $\mathrm{Yi}$, \& Singh, 1991). The composite reliability values ranged from 0.774 to 0.866 which exceeded the recommended values of 0.7 (Hair et al., 2016). Additionally, the AVE values of all the variables are in the range of 0.502 to 0.611 which exceeded the recommended value of 0.5 (Hair et al., 2016).

Following the convergent validity, Fornell and Larcker's (1981) approach is used to assess the discriminant validity. All the scales appeared to have a substantially higher square root of the AVE values, in comparison to their correlation with other variables. This substantiates the discriminant validity, as displayed in Table 5. Based on this, it is deduced that the variables and items used in the measurement model are suitable to be used to test the structural model and the associated hypotheses.

\subsection{Structural Model Analysis}

Assuming that the hypothesised measurement model satisfy the validity and reliability assessment, we then proceed with the structural model analysis. The data fitted the model well $\chi^{2}(453)=309.116, p=.68$ which implies that the data fitted the model sufficiently. Furthermore, both the incremental (AGFI $=.93$, TLI $=.98$ and CFI $=.93$ ) and absolute index (RMSEA $=.00$ and GFI $=.99$ ) have achieved their cut-off values (Schumacker \& Lomax, 2010). Following this, the significance of the 
Table 4: Convergent Validity

\begin{tabular}{|c|c|c|c|c|}
\hline Variables & Items & Factor Loading & $\begin{array}{c}\text { Average Variance } \\
\text { Extracted }\end{array}$ & $\begin{array}{l}\text { Composite } \\
\text { Reliability }\end{array}$ \\
\hline $\begin{array}{l}\text { Wikipedia } \\
\text { Characteristics }\end{array}$ & $\begin{array}{l}\text { WIKC1 } \\
\text { WIKC2 } \\
\text { WIKC3 } \\
\text { WIKC4 } \\
\text { WIKC5 } \\
\text { WIKC6 }\end{array}$ & $\begin{array}{l}0.700^{* * *} \\
0.837^{* * *} \\
0.764^{* * *} \\
0.644^{* * *} \\
0.637^{* * *} \\
0.578^{* * *}\end{array}$ & 0.588 & 0.849 \\
\hline $\begin{array}{l}\text { Member } \\
\text { Interaction }\end{array}$ & $\begin{array}{l}\text { MI1 } \\
\text { MI2 } \\
\text { MI3 } \\
\text { MI4 }\end{array}$ & $\begin{array}{l}0.716^{* * *} \\
0.766^{* * *} \\
0.721^{* * *} \\
0.823^{* * *}\end{array}$ & 0.574 & 0.843 \\
\hline $\begin{array}{l}\text { Community } \\
\text { Participation }\end{array}$ & $\begin{array}{l}\text { CPA1 } \\
\text { CPA2 } \\
\text { CPA3 } \\
\text { CPA4 }\end{array}$ & $\begin{array}{l}0.838^{* * *} \\
0.853^{* * *} \\
0.757^{* * *} \\
0.663^{* * *}\end{array}$ & 0.610 & 0.861 \\
\hline $\begin{array}{l}\text { Community } \\
\text { Promotion }\end{array}$ & $\begin{array}{l}\text { CPR1 } \\
\text { CPR2 } \\
\text { CPR3 } \\
\text { CPR4 } \\
\text { CPR5 }\end{array}$ & $\begin{array}{l}0.644^{* * *} \\
0.630^{* * *} \\
0.768^{* * *} \\
0.812^{* * *} \\
0.758^{* * *}\end{array}$ & 0.527 & 0.846 \\
\hline $\begin{array}{l}\text { Community } \\
\text { Trust }\end{array}$ & $\begin{array}{l}\text { CT1 } \\
\text { CT2 } \\
\text { CT3 } \\
\text { CT4 }\end{array}$ & $\begin{array}{l}0.838^{* * *} \\
0.857^{* * *} \\
0.750^{* * *} \\
0.663^{* * *}\end{array}$ & 0.609 & 0.860 \\
\hline $\begin{array}{l}\text { Community } \\
\text { Identification }\end{array}$ & $\begin{array}{l}\mathrm{CI} 1 \\
\mathrm{CI} 2 \\
\mathrm{CI} 3 \\
\mathrm{CI} 4 \\
\mathrm{CI} 5\end{array}$ & $\begin{array}{l}0.611^{* * *} \\
0.692^{* * *} \\
0.762^{* * *} \\
0.690^{* * *} \\
0.762^{* * *}\end{array}$ & 0.597 & 0.831 \\
\hline $\begin{array}{l}\text { Knowledge } \\
\text { Sharing } \\
\text { Intention }\end{array}$ & $\begin{array}{l}\text { KSI1 } \\
\text { KSI2 } \\
\text { KSI3 } \\
\text { KSI4 }\end{array}$ & $\begin{array}{l}0.727^{* * *} \\
0.802^{* * *} \\
0.661^{* * *} \\
0.513^{* * *}\end{array}$ & 0.568 & 0.774 \\
\hline
\end{tabular}

Note: ${ }^{* *}$ The estimate is significant at the 0.01 level. 
Table 5: Discriminant Validity

\begin{tabular}{lccccccc}
\hline Variables & WIKC & MI & CPA & CPR & CT & CI & KSI \\
\hline WIKC & $\mathbf{0 . 7 6 6}$ & & & & & & \\
MI & 0.619 & $\mathbf{0 . 7 5 7}$ & & & & & \\
CPA & 0.588 & 0.752 & $\mathbf{0 . 7 8 1}$ & & & & \\
CPR & 0.645 & 0.626 & 0.601 & $\mathbf{0 . 7 2 5}$ & & & \\
CT & 0.678 & 0.736 & 0.637 & 0.650 & $\mathbf{0 . 7 8 0}$ & & \\
CI & 0.600 & 0.732 & 0.645 & 0.680 & 0.660 & $\mathbf{0 . 7 7 2}$ & \\
KSI & 0.539 & 0.685 & 0.654 & 0.557 & 0.648 & 0.677 & $\mathbf{0 . 7 5 3}$ \\
\hline
\end{tabular}

Note: WIKC $=$ Wikipedia Characteristics, $\mathrm{MI}=$ Member Interaction, $\mathrm{CPA}=$ Community Participation, $\mathrm{CPR}=$ Community Promotion, $\mathrm{CT}=$ Community Trust, $\mathrm{CI}=$ Community Identification, KSI = Knowledge Sharing Intention .

Table 6: Path Estimate among Variables in the Structural Equation Modeling

\begin{tabular}{|c|c|c|c|c|c|c|}
\hline Hypotheses & $\begin{array}{c}\text { Structural Path } \\
\text { Estimate }\end{array}$ & $\beta$ & S.E. & t-value & $\mathrm{p}$-value & $\begin{array}{c}\text { Accepted/ } \\
\text { Rejected }\end{array}$ \\
\hline $\mathrm{H}_{1}$ & $\leftarrow$ WIKC & 0.550 & 0.065 & 8.417 & $* * *$ & Accepted \\
\hline $\mathrm{H}_{2 \mathrm{a}}$ & $\mathrm{CPA} \leftarrow \mathrm{MI}$ & 1.027 & 0.130 & 7.882 & $* * *$ & Accepted \\
\hline $\mathrm{H}_{2 \mathrm{~b}}$ & $\mathrm{CPR} \leftarrow \mathrm{MI}$ & 0.202 & 0.099 & 2.026 & $* *$ & Accepted \\
\hline $\mathrm{H}_{2 \mathrm{c}}$ & $\mathrm{CT} \leftarrow \mathrm{MI}$ & 0.736 & 0.097 & 7.597 & $* * *$ & Accepted \\
\hline $\mathrm{H}_{2 \mathrm{~d}}$ & $\mathrm{CI} \leftarrow \mathrm{MI}$ & 0.703 & 0.102 & 6.859 & $* * *$ & Accepted \\
\hline $\mathrm{H}_{3}$ & $\mathrm{CPR} \leftarrow \mathrm{CT}$ & 0.787 & 0.120 & 6.538 & $* * *$ & Accepted \\
\hline $\mathrm{H}_{4}$ & $\mathrm{CPA} \leftarrow \mathrm{CPR}$ & -0.066 & 0.082 & -.807 & 0.419 & Rejected \\
\hline $\mathrm{H}_{5 \mathrm{a}}$ & $\mathrm{KSI} \leftarrow \mathrm{CPA}$ & -0.084 & 0.069 & -1.219 & 0.223 & Rejected \\
\hline $\mathrm{H}_{5 \mathrm{~b}}$ & $\leftarrow \mathrm{CPR}$ & 0.054 & 0.113 & 0.482 & 0.630 & Rejected \\
\hline $\mathrm{H}_{5 \mathrm{c}}$ & $\leftarrow \mathrm{CT}$ & 0.356 & 0.135 & 2.633 & ** & Accepted \\
\hline $\mathrm{H}_{5 \mathrm{~d}}$ & $\leftarrow \mathrm{CI}$ & 0.619 & 0.079 & 7.807 & $* * *$ & Accepted \\
\hline
\end{tabular}

Note: ${ }^{* * *}$ The estimate is significant at the 0.01 level; ${ }^{* *}$ the estimate is significant at the 0.05 level; ${ }^{*}$ the estimate is significant at the 0.10 level.

direct effects, as specified by the research model, is further evaluated. Table 6 illustrates.

The results revealed that the effects of the Wikipedia characteristics $(\beta=0.55, \mathrm{p}<0.001)$ on member interaction is positive and significant, thereby supporting $\mathrm{H}_{1}$. This is consistent with previous findings (Wasko \& Faraj, 2000). The Wikipedia characteristics served as a knowledge 
platform which enabled the respective individuals to exhibit their expertise and capabilities. This is accomplished through knowledge sharing in the respective entries, thereby providing a good prospect for members to interact. Since members using Wikipedia have a choice of using a virtual account or to remain anonymous when they contribute to the contents, there is a possibility that there would be higher member interactions (Yang \& Lai, 2011) in the Wikipedia platform. The reason is because these members would have higher levels of confidence in displaying their competencies and to communicate.

The effects of member interaction on community participation $(\beta=$ $1.03, \mathrm{p}<0.001)$, community promotion $(\beta=0.20, \mathrm{p}<0.05)$, community trust $(\beta=0.74, \mathrm{p}<0.001)$, and community identification $(\beta=0.70, \mathrm{p}<$ 0.001 ) are all positive and significant, thereby supporting $\mathrm{H}_{2 \mathrm{a}}, \mathrm{H}_{2 \mathrm{~b}}, \mathrm{H}_{2 \mathrm{c}}$ and $\mathrm{H}_{2 \mathrm{~d}}$. In addition, community trust is found to have a significant positive relationship on community promotion, thereby supporting $\mathrm{H}_{3}$. These findings are expected and they are also in line with the results reported by $\mathrm{Qu}$ and Lee (2011). This outcome indicates that highly interactive members who are attached to Wikipedia are more likely to participate and to promote the virtual community to others (Feng \& Morrison, 2007). They perceive themselves as members as a result of their sense of belonging to the community.

In contrast, the effect of community promotion on community participation $(\beta=-0.066, \mathrm{p}=0.42)$; and the effect of community participation $(\beta=-0.084, p=0.22)$ and community promotion $(\beta=0.054$, $\mathrm{p}=0.63)$ on knowledge sharing intention is not significant, hence providing insubstantial evidence to support $\mathrm{H}_{4}, \mathrm{H}_{5 \mathrm{a}}$ and $\mathrm{H}_{5 \mathrm{~b}}$. Several plausible reasons could be the cause of the insignificant relationship. First, while member interaction may lead to community participation and community promotion, social interaction in Wikipedia, unlike other general virtual communities, is infrequent. Individuals who joined Wikipedia may not join the same community. Moreover, the contents shared tend to focus on specific technical issues which may not be of interest to others (Yang \& Lai, 2011). Therefore, even though there is substantial community promotion, it may not necessarily lead to community participation and individual willingness to share knowledge.

In line with Liao et al. (2013), this study also provides a positive significant effect of community trust $(\beta=0.36, \mathrm{p}<0.05)$ and community identification $(\beta=0.62, p<0.001)$ on knowledge sharing intention, thereby supporting $\mathrm{H}_{5 \mathrm{c}}$ and $\mathrm{H}_{5 \mathrm{~d}}$. This is expected as members who 
appear to trust the contents of the entries in Wikipedia may also exhibit a higher level of willingness to share the knowledge even though Wikipedia has no expert review mechanism. In most cases, individuals revise the entries when they believe that the original entries are inaccurate (Yang \& Lai, 2011). It is further speculated that members' overall trust towards the Wikipedia entries may be related to their individual experience and expertise. A user of the Wikipedia with increased community identification is more prone towards showing positive behaviours; he is more likely to have frequent exchanges of information and experiences with others.

\subsection{Differences between Italian and Indonesian Samples}

Following the structural model analysis of the two groups of samples, a multi-group analysis is performed to analyse the differences between the Italian and Indonesian samples. As indicated in Figure 3, there are significant differences between the two groups with regards to the relationship between member interaction and community promotion, and community participation and knowledge sharing. Within the Italian context, member interaction is found not to influence community promotion while community participation do not eventually lead to knowledge sharing. In contrast, the Indonesian samples are more likely to promote the virtual community platform when there is greater interaction between the members; participation in the virtual community will lead to higher intention to share knowledge.

These findings indicate that while there is high member interaction within the Wikipedia community, Italian students are not willing to promote the online community and share the knowledge. The inconsistent findings drawn from this study could be due to the cultural variations of the two groups of samples. Originating from a Western country, Italian students are characterised by their individualistic culture (Hofstede, 1998; Lin \& Ho, 2018). In an individualistic environment, members tend to consider personal interests and goals to be more important than the interests and goals shared by a group. Naturally, this outcome contradicted the Indonesian values which were characterised by a collectivistic society where the feelings, beliefs and behavioural intentions of the members very much depend on shared values, collaboration and coordination (Lin, 2014). In a highly collectivistic environment, members are willing to tolerate with low usability if the 


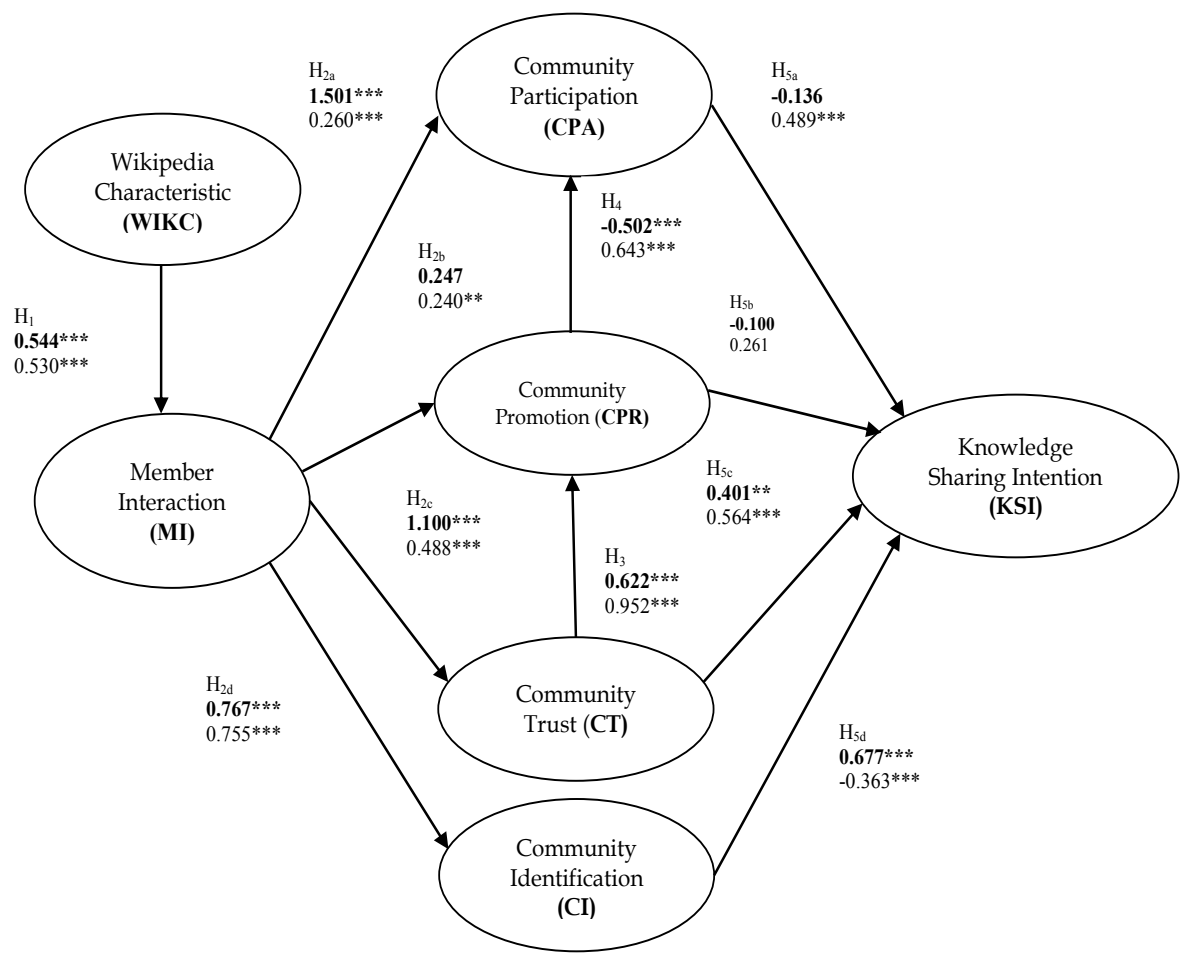

Figure 3: Path Analysis Output of Virtual Community Outcomes for Both Sample Groups (Italian and Indonesian Groups)

Note: The bold number is the path estimate for Italian group of sample and the nonbold is for Indonesian.

tool helps to achieve a shared goal of the society. Due to these reasons, individuals of the collectivistic society such as Indonesia are, thus, more incline to participate and share the knowledge through the virtual community even if the information posted may not benefit them. In comparison, being in a high uncertainty avoidance culture, people in Italy may prefer stability, predictability and resistance. Therefore, they would feel discomfort when they feel that their future is uncertain. In this regard, they tend not to circulate any knowledge and information if they themselves are not confident and certain about the credibility and quality of the information shared through Wikipedia. Figure 3 illustrates. 


\section{Conclusion and Implications}

The purpose of this study is to investigate the relationship between Wikipedia characteristics, member interaction, virtual community outcomes and knowledge sharing intention. Results generated from this study suggest that virtual community outcomes depend on the Wikipedia characteristics and member interaction. Increased interaction and Wikipedia characteristics brought about a strong identity within the community and further enhanced promotion, trust and participation. Nevertheless, since the Wikipedia has less or infrequent member interactions as compared to other general virtual community platforms, its promotion may not lead to participation nor the willingness of members to share knowledge substantially. The findings generated from this study show a variation between the Italian and Indonesian samples which could be attributed to their difference in cultural values and behaviours. Unlike the Indonesian students, the Italian students are only willing to promote the Wikipedia community if they feel that the quality of the information posted is relevant and if they have a good relationship with Wikipedia. Originating from a Western country, the Italian respondents may expect to see a more comprehensive and complete answer in the Wikipedia platform. Therefore, they would perceive any incomplete answers or contents as incapable of being considered for discussions, unlike their Indonesian contemporaries.

The findings of this study may offer some practical implications for the way online socialisation supports knowledge sharing within the university context. In this regard, the positive impact of member interaction and virtual community outcomes necessitate a proactive focus. To foster a sense of community identification, the virtual community platform such as Wikipedia, should provide tools that can make members feel connected with other members. The notification of response and the detailed profiles of members are among the characteristics that could be relied on to promote community identification. Additional tools to increase member interaction can be achieved through formal discussion featuring experts. This would enable members to communicate more directly within their interest, thereby promoting a greater level of trust. This would eventually lead to greater community promotion and community participation. It would also help to address some of the issues concerning the quality of the contents written for Wikipedia, which have suffered many criticisms. Featuring more experts and detailed profiles of members may instil a higher confidence 
on the entries made by contributors. This can ensure information completeness and accuracy through "collective wisdom". The credibility of the Wikipedia entries may involve an individual's trust towards the Wikipedia contents which may be related to the contributors' experience, thoughts and expertise.

While this study has offered an insight into the use of the Wikipedia platform as a knowledge sharing medium, several limitations were detected. The first of these is the generalisability of the results due to the use of only two groups of samples from two countries. Future research needs to consider collecting data from several other countries and from more diverse respondents with different educational backgrounds. Doing so will be able to shed light on whether users of the online-based (virtual) community of practice from different geographical locations share a similar propensity on knowledge sharing intentions. The second limitation is that the survey is confined to undergraduate students in two universities in Italy and Indonesia only. Future research should be extended to evaluate the perspective of other users and members since they too are important and relevant parties in the development of the online community of practice such as the Wikipedia. Future research may consider measuring and evaluating the different behaviors of users and members while using the online community of practice as alternative platforms of the physical community of practice.

Overall, this study also poses a challenge for future researchers to create more sophisticated assessment tools to measure how and why the perception of users and members may determine the sustainability of online-based community of practice. We believe that by delineating the effect of online-based community of practice, the behaviour of users and members, in terms of knowledge sharing intention, and by displaying the mediating role of online-based community of practice and knowledge sharing intention, future studies will be able to elaborate through more systematic procedures how the pattern of online-based community of practice can be developed.

\section{References}

Anderson, J.C.J., \& Gerbing, D.D.W. (1988). Structural equation modeling in practice: A review and recommended two-step approach. Psychological Bulletin, 103(3), 411-423. http://dx.doi.org/10.1037/0033-2909.103.3.411

Ardichvili, A., Page, V., \& Wentling, T. (2003). Motivation and barriers to participation in virtual knowledge-sharing communities of practice. Journal of 
Knowledge Management, 7(1), 64-77. http://dx.doi.org/10.1108/13673270 310463626

Arnett, D.B., German, S.D., \& Hunt, S.D. (2003). The identity salience model of relationship marketing success: The case of nonprofit marketing. Journal of Marketing, 67(2), 89-105. http://dx.doi.org/10.1509/jmkg.67.2.89.18614

Bagozzi, R.P., Yi, Y., \& Singh, S. (1991). On the use of structural equation models in experimental designs: Two extensions. International Journal of Research in Marketing, 8(2), 125-140. http:/ / dx.doi.org/10.1016/0167-8116(91)90020-8

Balasubramanian, S., \& Mahajan, V. (2001). The economic leverage of the virtual community. International Journal of Electronic Commerce, 5(3), 103-138. http:/ / dx.doi.org/10.1080/10864415.2001.11044212

Barker, R. (2015). Management of knowledge creation and sharing to create virtual knowledge-sharing communities: A tracking study. Journal of Knowledge Management, 19(2), 334-350. http:/ / dx.doi.org/10.1108/JKM-062014-0229

Bettiol, M., Di Maria, E., \& Grandinetti, R. (2012). Codification and creativity: Knowledge management strategies in KIBS. Journal of Knowledge Management, 16(4), 550-562. http:/ / dx.doi.org/10.1108/13673271211246130

Black, E.W. (2008). Wikipedia and academic peer review: Wikipedia as a recognised medium for scholarly publication? Online Information Review, 32(1), 73-88. http:/ / dx.doi.org/10.1108/14684520810865994

Bruns, A., \& Humphreys, S. (2005, October). Wikis in teaching and assessment: The M/Cyclopedia project. Paper presented at the 2005 International Symposium on Wikis, San Diego, California, USA. http:/ /dx.doi.org/10.1145/1104973. 1104976

Casimir, G., Lee, K., \& Loon, M. (2012). Knowledge sharing: Influences of trust, commitment and cost. Journal of Knowledge Management, 16(5), 740-753. http://dx.doi.org/10.1108/13673271211262781

Chiu, C.-M., Hsu, M.-H., \& Wang, E.T.G. (2006). Understanding knowledge sharing in virtual communities: An integration of social capital and social cognitive theories. Decision Support Systems, 42(3), 1872-1888. http:/ / dx.doi. org/10.1016/j.dss.2006.04.001

Chiu, C.-M., Wang, E.T.G., Shih, F.-J., \& Fan, Y.-W. (2011). Understanding knowledge sharing in virtual communities: An integration of expectancy disconfirmation and justice theories. Online Information Review, 35(1), 134153. http:/ / dx.doi.org/10.1108/14684521111113623

Di Maria, E., \& Finotto, V. (2008). Communities of consumption and made in Italy. Industry and Innovation, 15(2), 179-197. http://dx.doi.org/10.1080/ 13662710801954583

Ebner, M., Kickmeier-Rust, M., \& Holzinger, A. (2008). Utilizing wiki systems in higher education classes: A chance for universal access? Universal Access in the Information Society, 7(4), 199-207. http:/ / dx.doi.org/10.1007/s10209-0080115-2 
Elrufaie, E., \& Turner, D.A. (2005, April). A Wiki paradigm for use in IT courses. Paper presented at the International Conference on Information Technology: Coding and Computing, Las Vegas, USA. http://dx.doi.org/ 10.1109/ITCC.2005.54

Feng, R., \& Morrison, A.M. (2007). Quality and value network marketing travel clubs. Annals of Tourism Research, 34(3), 588-609. http://dx.doi.org/ 10.1016/j.annals.2007.01.006

Fornell, C., \& Larcker, D. (1981). Evaluating structural equation models with unobservable variables and measurement error. Journal of Marketing Research, 18(1), 39-50. http://dx.doi.org/10.2307/3151312

Gray, B. (2004). Informal Learning in an Online Community of Practice. Journal of Distance Education, 19(1), 20-35.

Gray, D.E., \& Gabriel, Y. (2018). A community of practice or a working psychological group? Group dynamics in core and peripheral community participation. Management Learning, 49(4), 395-412. http://dx.doi. org/10.1177/1350507618761774

Hafeez, K., Alghatas, F.M., Foroudi, P., Nguyen, B., \& Gupta, S. (2018). Knowledge sharing by entrepreneurs in a virtual community of practice (VCoP). Information Technology and People. http://dx.doi.org/10.1108/ITP09-2016-0202

Hair Jr, J.F., Hult, G.T.M., Ringle, C., \& Sarstedt, M. (2016). A primer on Partial Least Squares Structural Equation Modeling (PLS-SEM). Thousand Oaks, CA: SAGE Publications.

Hansen, S., Berente, N., \& Lyytinen, K. (2009). Wikipedia, critical social theory, and the possibility of rational discourse. The Information Society, 25(1), 3859. http://dx.doi.org/10.1080/01972240802587562

Hendriks, P. (1999). Why share knowledge? The influence of ICT on the motivation for knowledge sharing. Knowledge and Process Management, 6(2), 91-100. http://dx.doi.org/10.1002/(SICI)1099-1441(199906)6:2<91::AIDKPM54>3.0.CO;2-M

Hofstede, G. (1998). Attitudes, values and organizational culture: Disentangling the concepts. Organization Studies, 19(3), 477-493. http://dx.doi.org/ 10.1177/017084069801900305

Jansen, B.J., Sobel, K., \& Cook, G. (2011). Classifying ecommerce information sharing behaviour by youths on social networking sites. Journal of Information Science, 37(2), 120-136. http:/ / dx.doi.org/10.1177/0165551510396975

Jensen, M.B., Johnson, B., Lorenz, E., \& Lundvall, B.Å. (2007). Forms of knowledge and modes of innovation. Research Policy, 36(5), 680-693. http://dx. doi.org/10.1016/j.respol.2007.01.006

Johnson, C.M. (2001). A survey of current research on online communities of practice. The Internet and Higher Education, 4(1), 45-60. http://dx.doi. org/10.1016/S1096-7516(01)00047-1

Kim, Y., Sohn, D., \& Choi, S.M. (2011). Cultural difference in motivations for using social network sites: A comparative study of American and Korean 
college students. Computers in Human Behavior, 27(1), 365-372. http://dx. doi.org/10.1016/j.chb.2010.08.015

Koh, J., \& Kim, Y.-G. (2004). Knowledge sharing in virtual communities: An e-business perspective. Expert Systems with Applications, 26(2), 155-166. http://dx.doi.org/10.1016/S0957-4174(03)00116-7

Korfiatis, N.T., Poulos, M., \& Bokos, G. (2006). Evaluating authoritative sources using social networks: An insight from Wikipedia. Online Information Review, 30(3), 252-262. http://dx.doi.org/10.1108/14684520610675780

Lee, H.-Y., Ahn, H., \& Han, I. (2007). VCR: Virtual community recommender using the technology acceptance model and the user's needs type. Expert Systems with Applications, 33(4), 984-995. http://dx.doi.org/10.1016/j.eswa. 2006.07.012

Leuf, B., \& Cunningham, W. (2001). The wiki way: Quick collaboration on the web. Upper Saddle River, NJ, USA: Addison Wesley.

Liao, C., To, P.-L. \& Hsu, F.-C. (2013). Exploring knowledge sharing in virtual communities. Online Information Review, 37(6), 891-909. http://dx.doi.org/ 10.1108/OIR-11-2012-0196

Lin, H.-C. (2014). An investigation of the effects of cultural differences on physicians' perceptions of information technology acceptance as they relate to knowledge management systems. Computers in Human Behavior, 38(September), 368-380. http://dx.doi.org/10.1016/j.chb.2014.05.001

Lin, H.-C., \& Ho, W.-H. (2018). Cultural effects on use of online social media for health-related information acquisition and sharing in Taiwan. International Journal of Human-Computer Interaction, 34(11), 1063-1076. http://dx.doi.org /10.1080/10447318.2017.1413790

Massingham, P. (2014). An evaluation of knowledge management tools: Part 1 - managing knowledge resources. Journal of Knowledge Management, 18(6), 1075-1100. http://dx.doi.org/10.1108/JKM-11-2013-0449

Md Rasli, A., \& Wan Mohd, W.M. (2007). Project performance framework: The role of knowledge management and information technology infrastructure. Asian Journal of Business and Accounting , 1(2), 39-64.

Molm, L.D. (1997). Coercive power in social exchange. Cambridge, UK: Cambridge University Press.

Nonaka, I. (1994). A dynamic theory of organizational knowledge creation. Organization Science, 5(1), 14-37. http://dx.doi.org/10.1287/orsc.5.1.14

Parker, K.R., \& Chao, J.T. (2007). Wiki as a teaching tool. Interdisciplinary Journal of Knowledge and Learning Objects, 3(1), 57-72.

Pee, L.G. (2018). Community's knowledge need and knowledge sharing in Wikipedia. Journal of Knowledge Management, 22(4), 912-930. http://dx.doi. org/10.1108/JKM-09-2017-0412

Qu, H., \& Lee, H. (2011). Travelers' social identification and membership behaviors in online travel community. Tourism Management, 32(6), 12621270. http://dx.doi.org/10.1016/j.tourman.2010.12.002

Rector, L.H. (2008). Comparison of Wikipedia and other encyclopedias for 
accuracy, breadth, and depth in historical articles. Reference Services Review, 36(1), 7-22. http://dx.doi.org/10.1108/00907320810851998

Romm, C., Pliskin, N., \& Clarke, R. (1997). Virtual communities and society: Toward an integrative three phase model. International Journal of Information Management, 17(4), 261-270. http://dx.doi.org/10.1016/S02684012(97)00004-2

Schumacker, R.E., \& Lomax, R.G. (2010). A beginner's guide to structural equation modeling (3rd ed). Mahwah, New Jersey: Lawrence Erlbaum Associates.

Schwen, T.M., \& Hara, N. (2003). Community of practice: A metaphor for online design? The Information Society, 19(3), 257-270. http://dx.doi.org/10.1080/ 01972240309462

Shaw, A., \& Hargittai, E. (2018). The pipeline of online participation inequalities: The case of Wikipedia editing. Journal of Communication, 68(1), 143-168. http://dx.doi.org/10.1093/joc/jqx003

Stats, I.W. (2018). Top 20 countries with the highest number of Internet users. Retrieved from https://www.internetworldstats.com/top20.htm

Trkman, M., \& Trkman, P. (2009). A wiki as intranet: A critical analysis using the Delone and McLean model. Online Information Review, 33(6), 1087-1102. http://dx.doi.org/10.1108/14684520911011025

Wang, C.M., \& Turner, D. (2004). Extending the wiki paradigm for use in the classroom. In Proceedings of the International Conference on Information Technology: Coding Computing, ITCC (Vol. 1, pp. 255-259).

Wang, W.-T., \& Wei, Z.-H. (2011). Knowledge sharing in wiki communities: An empirical study. Online Information Review, 35(5), 799-820. http://dx.doi. org/10.1108/14684521111176516

Wasko, M.M., \& Faraj, S. (2000). "It is what one does": Why people participate and help others in electronic communities of practice. The Journal of Strategic Information Systems, 9(2-3), 155-173. http://dx.doi.org/10.1016/ S0963-8687(00)00045-7

Wenger, E. (2003). Communities of practice: Learning, meaning and identity. Cambridge, UK: Cambridge University Press.

Wenger, E., \& Trayner-Wenger, B. (2015). Communities of practice: A brief introduction. Retrieved from http://wenger-trayner.com/wp-content/ uploads/2015/04/07-Brief-introduction-to-communities-of-practice.pdf

Wikipedia. (2017). Wikipedia: Size of Wikipedia. Retrieved from https://en.wiki pedia.org/wiki/Wikipedia:Size_of_Wikipedia\#cite_notestats.wikimedia-1

WMF Analytics. (2018). Wikipedia Statistics: Contributors. Retrieved from https:/ / stats.wikimedia.org/EN/TablesWikipediansContributors.htm

Yang, H.-L., \& Lai, C.-Y. (2011). Understanding knowledge-sharing behaviour in Wikipedia. Behaviour \& Information Technology, 30(1), 131-142. http:// dx.doi.org/10.1080/0144929X.2010.516019

Zhang, Y., Fang, Y., Wei, K.-K., \& Chen, H. (2010). Exploring the role of psychological safety in promoting the intention to continue sharing knowledge in virtual communities. International Journal of Information Management, 30(5), 425-436. http://dx.doi.org/10.1016/j.ijinfomgt.2010.02.003 